\title{
EFECTO ANTIOXIDANTE Y ANTIFOTOENVEJECIMIENTO DE EXTRACTOS DE LA MACROALGA DEL LITORAL PERUANO DE Macrocystis integrifolia BORY Y ELABORACIÓN DE UNA FORMA DERMOCOSMÉTICA
}

\author{
Antioxidant and antiphotoaging effects of extracts of seaweed peruvian coastal Macrocystis \\ integrifolia Bory and development of a dermocosmetic form
}

Américo J. Castro ${ }^{1}$, José R. Juárez ${ }^{1}$, Silvia Suárez ${ }^{2}$, Mario Alcarraz $^{3}$, Norma J. Ramos ${ }^{1}$, Luis Hinostroza ${ }^{1}$, Ernesto Ráez ${ }^{4}$, Juan J. Ponce ${ }^{1}$, Omar Santa María ${ }^{1}$, Paul Gutiérrez ${ }^{1}$, Ruth J. Lucas ${ }^{1}$, Walter R. Vicente ${ }^{1}$, Gianina L. Giurfa ${ }^{1}$, Jean Piere Oblitas ${ }^{1}$, Fritz F. Choquesillo ${ }^{1}$

${ }^{1}$ Instituto de Investigación en Ciencias Farmacéuticas y Recursos Naturales “Juan de Dios Guevara”, Facultad de Farmacia y Bioquímica. ${ }^{2}$ Centro de Investigación en Bioquímica y Nutrición “Alberto Guzmán Barrón”, Facultad de Medicina. ${ }^{3}$ Instituto de Investigación “Antonio Raimondi”, Facultad de Ciencias Biológicas. ${ }^{4}$ Instituto de Patología, Facultad de Medicina. Universidad Nacional Mayor de San Marcos

\section{RESUMEN}

El objetivo del estudio fue evaluar el efecto antioxidante y antifotoenvejecimiento de extractos de la alga parda Macrocystis integrifolia Bory y elaborar una forma dermocosmética. Obtenidos los extractos, se diseñó una forma dermocosmética en concentraciones de 1, 3 y 5\%, elaboradas sobre una base de manteca de cerdo con incorporación de cera de abejas y aceite de sésamo a un $\mathrm{pH}$ de 6,5. La actividad antioxidante in vitro se determinó por lo métodos CDP y ABTS. La evaluación del efecto antifotoenvejecimiento in vivo se realizó empleando 25 ratones albinos hembra de la especie Mus musculus, cepa Bald/C53, que fueron distribuidos en cinco grupos de cinco ratones cada uno; a excepción del grupo que sirvió de blanco, el grupo control y los grupos de intervención fueron depilados en el lomo y se sometieron a la irradiación UVB durante 7 días, mañana y noche. El ensayo in vitro de la actividad antioxidante mostró que entre los extractos de estípite, fronda y bulbo de esta alga, existen diferencias en la capacidad antioxidante frente al radical libre ABTS, evidenciándose que el menor valor de $\mathrm{IC}_{50}(173,21 \mu \mathrm{g} / \mathrm{mL}) \mathrm{del}$ extracto de fronda presenta mayor capacidad antioxidante total que el valor $\mathrm{IC}_{50}(3,23 \mu \mathrm{g} / \mathrm{mL})$ de Trólox, sustancia de referencia. En el ensayo CDP se tuvo un valor de IC $50(669,7 \mu \mathrm{g} / \mathrm{mL})$ por encima del estándar del ácido ascórbico IC 50 (33 $\mu \mathrm{g} / \mathrm{mL})$. En el análisis antifotoenvejecimiento se observó, a niveles macro y microscópicos, notables diferencias favorables en los grupos de intervención. Se concluye que los extractos del alga parda estudiada tienen efecto antioxidante in vitro y antifotoenvejecimiento in vivo.

Palabras clave: Macrocystis integrifolia Bory, Mus musculus, in vitro, in vivo, antioxidante, antifotoenvejecimiento.

\section{SUMMARY}

The aim of the study was to evaluate the antioxidant and antiphotoaging effects of extracts of brown alga Macrocystis integrifolia Bory and develop a dermocosmetic form. From this extracts, was designed the dermocosmetic form in concentrations of 1, 3 and 5\%, on a base made of lard with incorporation of beeswax and sesame oil to a pH of 6,5. The antioxidant activity was determined by in vitro methods as CDP and ABTS. The evaluation of antiphotoaging effect in vivo was performed using 25 albino female mice of Mus musculus specie, strain Bald / $\mathrm{C}_{53}$, who were divided into five groups of five mice each; except the group that served as blank, control and intervention groups were depilated hair back and subjected to UVB irradiation for 7 days, morning and night. The in vitro antioxidant activity assay showed that between extracts from stem, foliage and bulb of this alga, there are differences in antioxidant capacity against free radical ABTS, stating that the lower IC 50 value $(173,21 \mu \mathrm{g} / \mathrm{mL})$ frond abstract presents higher total antioxidant capacity than the IC $50(3,23 \mu \mathrm{g} / \mathrm{mL}) \mathrm{value} \mathrm{of}$ Trolox, reference substance. In the trial CDP an IC 50 value $(669,7 \mu \mathrm{g} / \mathrm{mL})$ was above the standard of ascorbic acid $\mathrm{IC}_{50}(33$ $\mu \mathrm{g} / \mathrm{mL}$ ). Antiphotoaging analysis showed, at macro and microscopic levels, favorable notable differences in the intervention groups. Was conclude that brown seaweed extracts studied have antioxidant effect in vitro and antiphotoaging in vivo.

Keywords: Macrocystis integrifolia Bory, Mus musculus, in vitro, in vivo, antioxidant, antiphotoaging.

\section{INTRODUCCIÓN}

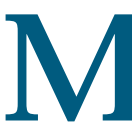

acrocystis integrifolia Bory es una macroalga grande y compleja que forma extensos bosques flotantes en o cerca de la superficie del mar constituyendo un valioso hábitat para muchas especies de peces e invertebrados ${ }^{(1)}$. Se distribuye desde Alaska, México, Perú, norte de Chile y California ${ }^{(2)}$. Esta alga es de color oscuro con un rizoma profusamente ramificado dicotómicamente, macizo, aplanado y alargado que le permite adherirse estrechamente al sustrato. Sus hojas son largas y angostas de superficie rugosa y márgenes levemente dentados. Las algas pardas producen una 
Tabla 1. Extractos hidroalcohólico del alga Macrocystis integrifolia Bory.

\begin{tabular}{cccc}
\hline Tubos & $\begin{array}{c}\text { Fronda } \\
\mathbf{m g} / \mathbf{m L}\end{array}$ & $\begin{array}{c}\text { Estípite } \\
\mathbf{m g} / \mathbf{m L}\end{array}$ & $\begin{array}{c}\text { Bulbo } \\
\mathbf{m g} / \mathbf{m L}\end{array}$ \\
\hline 1 & 5 & 10 & 10 \\
2 & 10 & 15 & 15 \\
3 & 15 & 20 & 20 \\
\hline
\end{tabular}

Tabla 2. Concentración de los extractos hidroalcohólico del alga Macrocystis integrifolia Bory en el tubo de reacción.

\begin{tabular}{cccc}
\hline Tubos & $\begin{array}{c}\text { Fronda } \\
\mu \mathrm{g} / \mathrm{mL}\end{array}$ & $\begin{array}{c}\text { Estípite } \\
\mu \mathrm{g} / \mathrm{mL}\end{array}$ & $\begin{array}{c}\text { Bulbo } \\
\mu \mathrm{g} / \mathrm{mL}\end{array}$ \\
\hline 1 & 100 & 200 & 200 \\
2 & 200 & 300 & 300 \\
3 & 300 & 400 & 400 \\
\hline
\end{tabular}

Tabla 3. Preparación de las diluciones de extracto hidroalcohólico de Macrocystis integrifolia.

\begin{tabular}{ccc}
\hline Tubos & $\begin{array}{c}\text { Concentración inicial } \\
{[\mathrm{mg} / \mathrm{mL}]}\end{array}$ & $\begin{array}{c}\text { Concentración final } \\
{[\mathrm{mg} / \mathrm{mL}]}\end{array}$ \\
\hline 1 & 1,2 & 0,8 \\
2 & 0,6 & 0,4 \\
3 & 0,3 & 0,2 \\
\hline
\end{tabular}

Tabla 4. Extracto hidroalcohólico de fronda.

\begin{tabular}{ccc}
\hline $\begin{array}{c}\text { Concentración } \\
(\mu g / \mathrm{mL})\end{array}$ & Absorbancia & \% de Inhibición \\
\hline 0 & 0,703 & - \\
100 & 0,445 & $36,77 \%$ \\
200 & 0,346 & $50,78 \%$ \\
300 & 0,288 & $78,02 \%$ \\
\hline
\end{tabular}

Tabla 5. Extracto hidroalcohólico de estípite.

\begin{tabular}{ccc}
\hline $\begin{array}{c}\text { Concentración } \\
(\mu \mathrm{\mu g} / \mathrm{mL})\end{array}$ & Absorbancia & \% de Inhibición \\
\hline 0 & 0,711 & - \\
200 & 0,512 & $28 \%$ \\
300 & 0,427 & $40 \%$ \\
400 & 0,352 & $50,5 \%$ \\
\hline
\end{tabular}

Tabla 6. Extracto hidroalcohólico de bulbo.

\begin{tabular}{ccc}
\hline $\begin{array}{c}\text { Concentración } \\
(\mu \mathrm{g} / \mathrm{mL})\end{array}$ & Absorbancia & \% de Inhibición \\
\hline 0 & 0,711 & - \\
200 & 0,4535 & $36,2 \%$ \\
300 & 0,373 & $47,5 \%$ \\
400 & 0,2895 & $59,5 \%$ \\
\hline
\end{tabular}

amplia variedad de metabolitos secundarios, los cuales incluyen terpenoides, oxilipinas, florotaninos, hidrocarburos volátiles y productos de origen biogenético mixto con actividad antioxidante y como inhibidores de diferentes enzimas ${ }^{(3)}$.

Estudios realizados en extractos de algas marinas, permitieronevaluarlaactividadantifotoenvejecimiento y antioxidante, encontrándose que al aplicar cremas preparadas a partir de algas en 25,50 y $100 \mathrm{mg} /$
$\mathrm{mL}$, sobre ratones machos después de irradiación ultravioleta, las alteraciones histopatológicas causadas disminuyeron o se atenuaron, demostrándose además, por evaluación bioquímica in vitro, que el mejor de los extractos poseía actividad superóxidodismutasa (SOD) $\mathrm{IC}_{5 \mathrm{O}}=1,71 \mathrm{mg} / \mathrm{mL}^{(4)}$. En estudios realizados mediante modelos biológicos similares, se han observado diferentes manifestaciones histopatológicas presentes en el fotoenvejecimiento, dentro de las que se pueden citar principalmente: engrosamiento del estrato córneo (hiperqueratosis), engrosamiento de la capa epidérmica (acantosis), infiltrado inflamatorio, aumento y desorganización de las fibras colágenas, aumento de la cantidad de fibras elásticas (elastosis) y congestión de los vasos sanguíneos ${ }^{(5)}$.

Por lo expuesto, el estudio tuvo como objetivo evaluar el efecto antioxidante y antifotoenvejecimiento de los extractos hidroalcohólicos de las partes de bulbo, fronda y estípite de Macrocystis integrifolia Bory, y la elaboración de su forma dermocosmética

\section{MATERIALES Y MÉTODOS}

\section{Colecta del material biológico}

La especie vegetal fue colectada en el zócalo continental de la playa Yanyarina de Marcona en la Región Ica y su clasificación taxonómica se realizó en el Museo de Historia Natural de la Universidad Nacional Mayor de San Marcos, según el sistema de clasificación de Guiry, M.D. \& Guiry G.M. 2013:

$$
\begin{array}{ll}
\text { División } & \text { : Phaeophyta } \\
\text { Clase } & \text { : Pheophyceae } \\
\text { Orden } & \text { : Laminariales } \\
\text { Género } & \text { : Macrocystis } \\
\text { Especie } & \text { : Macrocystis pyrifera (Linneapus) Agardh } \\
\text { Sinonimia } & \text { Macrocystisintegrifolia BorydeSaint-Vicent }
\end{array}
$$

\section{Obtención del extracto hidroalcohólico}

Las algas fueron lavadas con agua de mar y posteriormente con agua potable, procediéndose después a su secado, molienda y tamizado, pesándose 300 g decada una de sus partes (bulbo, estípitey frondas) que fueron sometidas a un proceso de maceración por siete días, con una mezcla hidroalcohólica etanol $96^{\circ}$-agua (1:1), con agitación, posterior filtración y evaporación del solvente a presión reducida.

\section{Formulación de la forma dermocosmética}

Con el extracto obtenido se diseñó la forma dermocosmética, vehiculizando el extracto en una base de manteca de cerdo, con incorporación de 


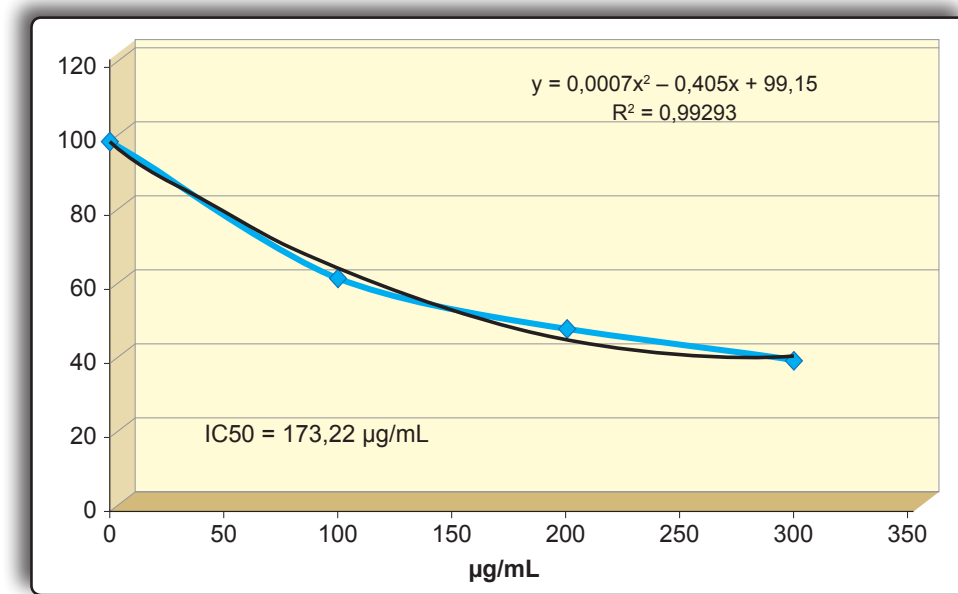

Figura 1. Concentración efectiva 50 (IC50) frente al ABTS del extracto hidroalcohólico de fronda de Macrocystis integrifolia Bory.

cera de abejas y aceite de sésamo a un $\mathrm{pH}$ de 6,5 en concentración de $1 ; 3$ y $5 \%$ del extracto.

\section{Determinación de la actividad antioxidante}

\section{Método de captación del radical libre catiónico ABTS}

El (ácido 2, 2' Azino-bis [3-etil- benzotiazolin-6 sulfonato]) o ABTS ${ }^{(6)}$, es una molécula orgánica estable, la forma de radical catiónico se preparó a partir de una solución acuosa stock $7 \mathrm{mM}$, se le añadió persulfato de potasio para una concentración final de 2,45 mM. Se dejó reaccionar durante 16 $\mathrm{h}$ a temperatura ambiente y en oscuridad.

Para los ensayos se realizó una dilución que exhibiera una absorbancia de 0,7 + 0,02.

\section{Preparación de las muestras con los extractos}

Se realizaron las diluciones de los extractos hidroalcohólicos de fronda, estípite y bulbo con una solución de etanol $96^{\circ}$-agua (7:3) a diferentes concentraciones, tabla 1.

El procedimiento para la reacción consistió en colocar $20 \mu \mathrm{L}$ de cada extracto y $980 \mu \mathrm{L}$ de ABTS. Se dejó en reposo, alejado de la luz durante 7 minutos. El tubo control contenía el radical libre ABTS y se leyó contra un blanco de agua. Se realizó la lectura de las absorbancias a 734 jm. Las concentraciones de los tres extractos en el tubo de reacción se muestran en el siguiente cuadro.

\begin{tabular}{|lccc|}
\hline & Blanco & Muestra & ABTS \\
\hline Agua destilada & $1 \mathrm{~mL}$ & - & - \\
ABTS & - & $980 \mu \mathrm{L}$ & $1 \mathrm{~mL}$ \\
Extracto & - & $20 \mu \mathrm{L}$ & - \\
hidroalcohólico & - & & - \\
\hline
\end{tabular}

Tabla 7. Efecto antifotoenvejecimiento del extracto hidroalcohólico de Macrocystis integrifolia Bory, vehiculizado en una forma dermocosmética, sobre piel de Mus Musculus irradiado con luz UVB cada 12 horas durante siete días.

\begin{tabular}{|c|c|c|}
\hline \multirow{2}{*}{ Durante siete días } & \multicolumn{2}{|r|}{ Después de siete días } \\
\hline & Análisis macroscópico & Análisis microscópico \\
\hline Grupo control irradiado & $\begin{array}{l}\text { Piel deshidratada } \\
\text { Arrugada } \\
\text { Áspera } \\
\text { Congestionada } \\
\text { Engrosamiento epidérmico }\end{array}$ & $\begin{array}{l}\text { Pérdida de la capa córnea } \\
\text { Edema superficial } \\
\text { Erosión y reacción inflamatoria } \\
\text { Destrucción y desorganización de las fibras colágenas } \\
\text { Alteración de las fibras elásticas }\end{array}$ \\
\hline $\begin{array}{l}\text { Grupo patrón con protector solar e } \\
\text { irradiado }\end{array}$ & $\begin{array}{l}\text { Piel deshidratada } \\
\text { Seca y escamosa } \\
\text { Arrugada } \\
\text { Congestionada } \\
\text { Engrosamiento epidérmico }\end{array}$ & $\begin{array}{l}\text { Pérdida de la capa córnea } \\
\text { Formación de ampollas } \\
\text { Tejido celular cutáneo ampollado entre la dermis y } \\
\text { epidermis } \\
\text { Células inflamadas } \\
\text { Erosión y detritus costroso. }\end{array}$ \\
\hline $\begin{array}{l}\text { Grupo de intervención irradiado y } \\
\text { con pomada al } 1 \%\end{array}$ & $\begin{array}{l}\text { Piel áspera } \\
\text { Levemente arrugada }\end{array}$ & $\begin{array}{l}\text { Capa córnea discontinua } \\
\text { Microampollas entre la epidermis y la capa muscular } \\
\text { Abundancia de tejido colágeno } \\
\text { Presencia de macrófagos y linfocitos en gran cantidad }\end{array}$ \\
\hline $\begin{array}{l}\text { Grupo de intervención irradiado y } \\
\text { con pomada al } 3 \%\end{array}$ & $\begin{array}{l}\text { Piel áspera } \\
\text { Levemente arrugada }\end{array}$ & $\begin{array}{l}\text { Pérdida de la capa córnea } \\
\text { Abundante colágeno en la dermis } \\
\text { Ausencia de células inflamadas } \\
\text { Microampollas en la dermis } \\
\text { Epidermis discontinua y delgada }\end{array}$ \\
\hline $\begin{array}{l}\text { Grupo de intervención irradiado y } \\
\text { con pomada al 5\% }\end{array}$ & $\begin{array}{l}\text { Piel áspera } \\
\text { Levemente arrugada }\end{array}$ & $\begin{array}{l}\text { Capa córnea laminar fragmentada } \\
\text { Epidermis delgada } \\
\text { Presencia de tejido colágeno } \\
\text { Microampollas en la dermis } \\
\text { Moderada inflamación }\end{array}$ \\
\hline
\end{tabular}




\begin{abstract}
Método de descomposición del peróxido de hidrógeno (CDP)

Bory dieron un rendimiento promedio de $45 \mathrm{~g}$. Con estos extractos se formuló la forma dermocosmética

De los extractos del alga se prepararon diluciones con en pomadas, con concentraciones de $1 ; 3$ y $5 \%$.
\end{abstract}

una solución de etanol $96^{\circ}$-agua (1:1), según la tabla 3.

La preparación del peróxido de hidrógeno 18 $\mathrm{mM}$ se realizó en buffer fosfato salino (PBS) empleando el coeficiente de extinción molar $\underline{81} \mathrm{M}^{-1} \mathrm{~cm}^{-1}$ a $230 \mathrm{jm}$. La absorbancia inicial del peróxido de hidrógeno fue 0,516 , que corresponde a una concentración de $6,37 \mathrm{mM}$.

El tubo de reacción, de $1,2 \mathrm{~mL}$ de volumen total, se preparó con $0,4 \mathrm{~mL}$ de peróxido de hidrógeno y o,8 mL de extracto. Se preparó un tubo blanco de extracto reemplazando el peróxido de hidrógeno por PBS. El tubo blanco de reactivo contenía además de peróxido de hidrógeno, o, $8 \mathrm{~mL}$ del solvente hidroalcohólico empleado para preparar las diluciones. La concentración final de los extractos se observa en la tabla 3.

Se empleó ácido ascórbico como estándar de referencia; se realizó una curva de calibración empleando concentraciones finales de 15 a 60 $\mu \mathrm{g} / \mathrm{mL}^{(7)}$. El procedimiento fue el mismo usado para las muestras de extracto.

\title{
Evaluación del efecto antifotoenvejecimiento
}

El estudio farmacológico se efectuó en 25 ratones albinos hembra Mus musculus, cepa Balb/C 53, de peso promedio $25 \mathrm{~g}$. Los ratones fueron separados en cinco grupos de cinco individuos cada uno, a los que se depiló el tercio anterior superior del lomo e irradió con luz UVB durante 7 días cada 12 horas por 30 minutos. El primer grupo fue control, el segundo patrón y los grupos tres, cuatro y cinco de intervención. Con excepción del grupo control, que solo fue irradiado con luz UVB y el grupo patrón al que se irradió con luz UVB y se le aplicó el bloqueador solar, a los grupos tres, cuatro y cinco se les irradió luz UVB y se les aplicó la forma dermocosmética en pomadas vehiculizadas con el extracto, en concentración de $1 ; 3$ y $5 \%$, respectivamente.

\section{RESULTADOS}

Los extractos hidroalcohólicos del bulbo, estípitey fronda del alga Macrocystis integrifolia

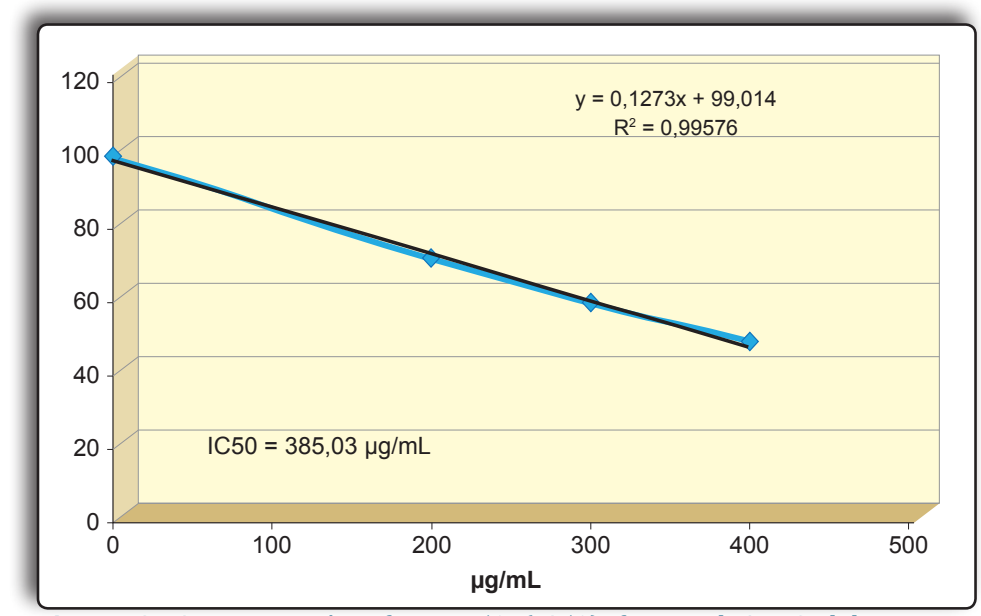

Figura 2. Concentración efectiva 50 (IC50) frente al ABTS del extracto hidroalcohólico de estípite de Macrocystis integrifolia Bory.

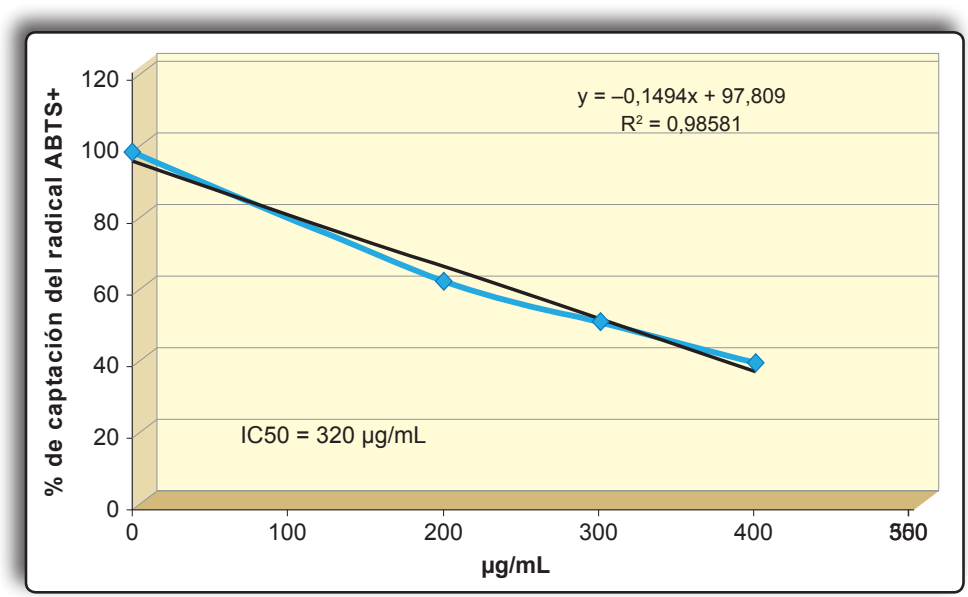

Figura 3. Concentración efectiva 50 (IC50) frente al ABTS del extracto hidroalcohólico de bulbo de Macrocystis integrifolia Bory.

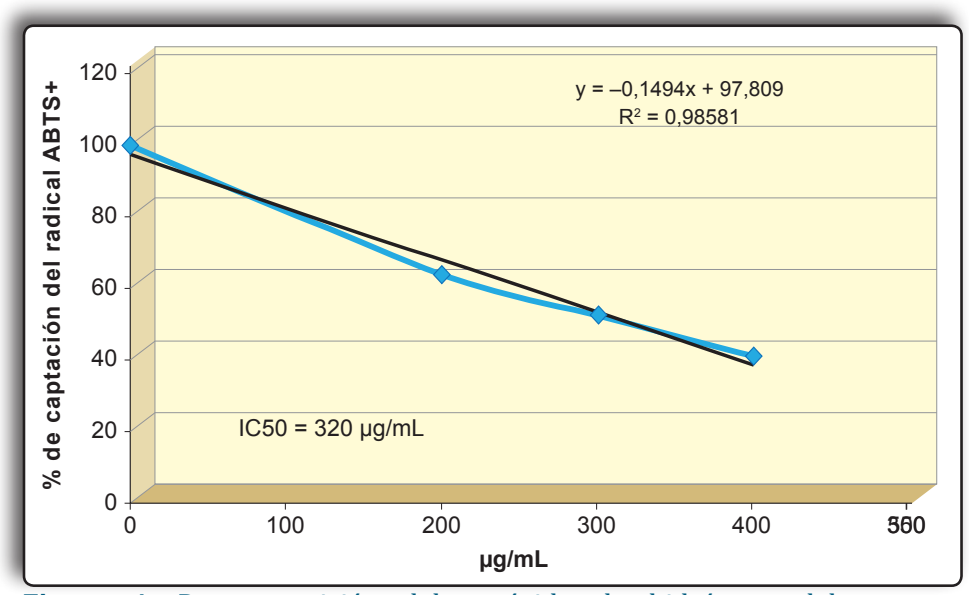

Figura 4. Descomposición del peróxido de hidrógeno del extracto hidroalcohólico de fronda de Macrocystis integrifolia Bory. 


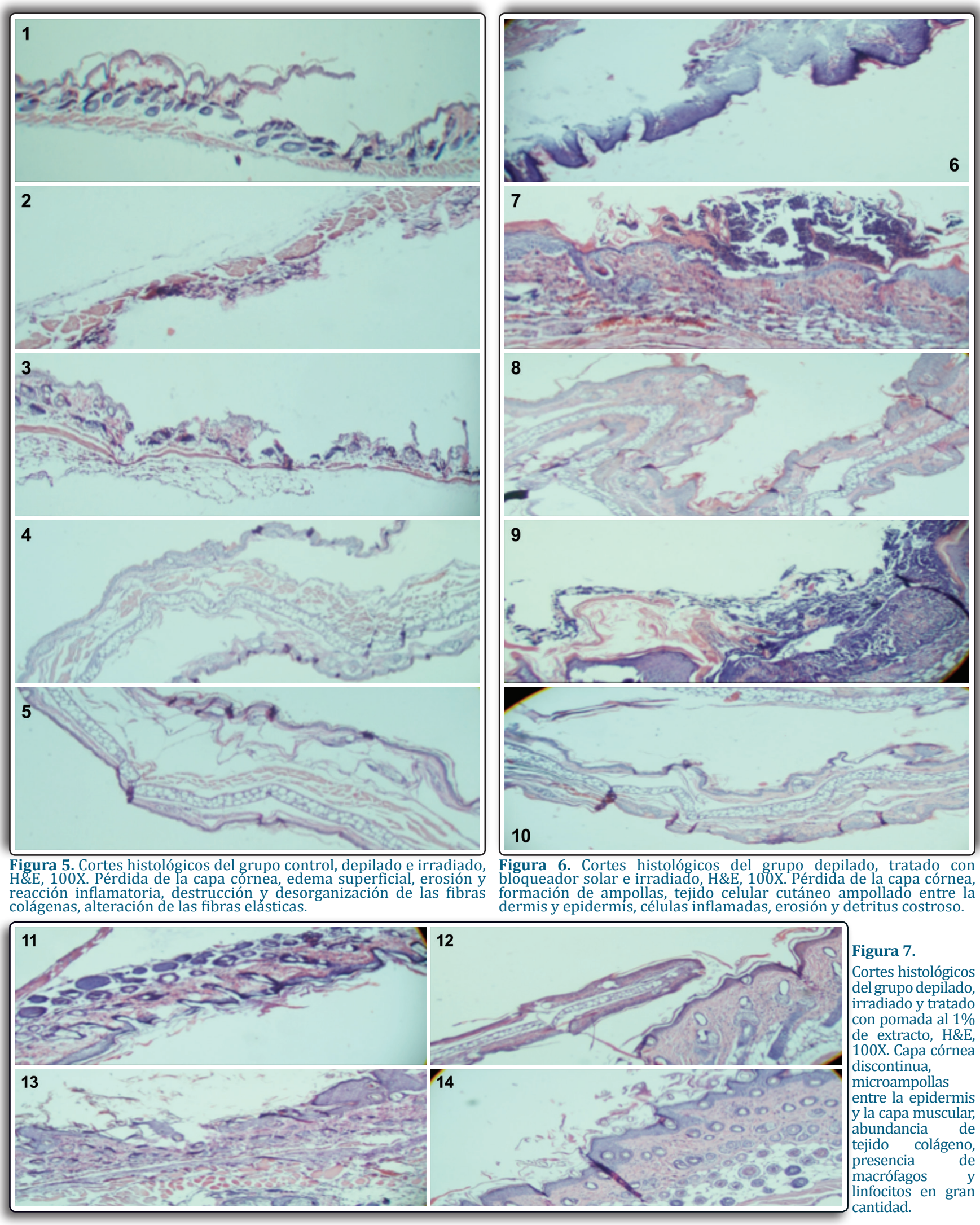


Determinación de la actividad antioxidante por el método del radical libre catiónico ABTS

Los resultados obtenidos para la capacidad antioxidante de los extractos hidroalcohólicos de fronda, estípite y bulbo se presentan en las tablas $4,5 \mathrm{y}$ 6 y en las figuras 1,2 y 3.

Determinación de la actividad antioxidante por el método de Descomposición del Peróxido de Hidrógeno (CDP)

Los resultados muestran un $\mathrm{IC}_{50}$ menor para el extracto de fronda, por lo que fue elegido para ser evaluado frente a especies reactivas del oxígeno: peróxido de hidrógeno y radical superóxido (figura 4).

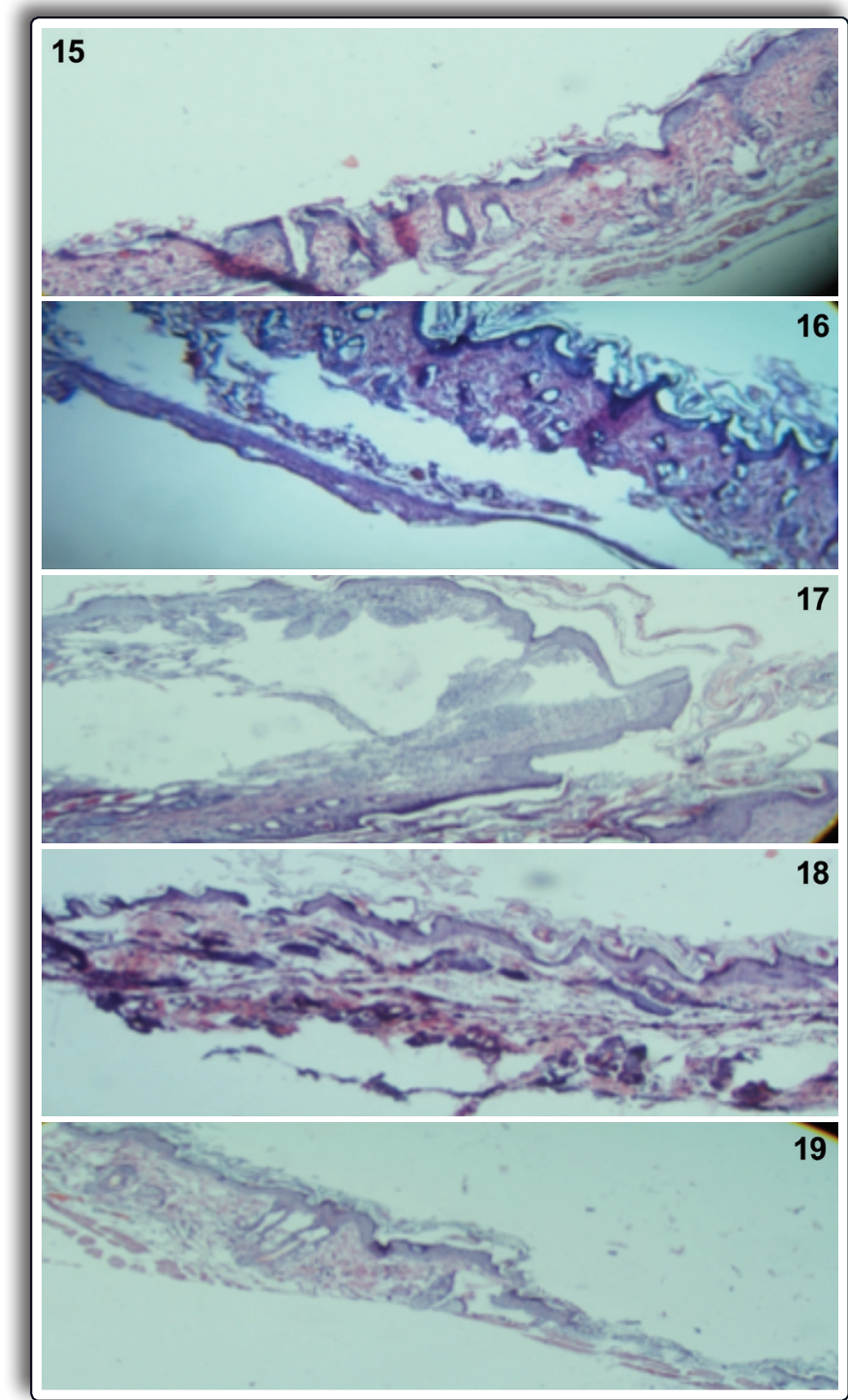

Figura 8. Cortes histológicos del grupo depilado, irradiado y tratado con pomada al 3\% de extracto, H\&E, 100X. Pérdida de la capa córnea, abundante colágeno en la dermis, ausencia de células inflamadas, microampollas en la dermis, epidermis discontinua y delgada.
Evaluación del efecto antifotoenvejecimiento del extracto hidroalcohólico de Macrocystis integrifolia Bory.

El análisis histopatológico del efecto antifotoenvejecimiento se realizó con el estudio del tejido del lomo anterior superior del ratón, al que se realizó la aplicación tópica del extracto hidroalcohólico vehiculizado en la forma de pomada en concentraciones de $1 ; 3$ y $5 \%$. Los resultados obtenidos se presentan en la tabla 7 y la observación de los cortes histopatológicos de los grupos control, patrón los grupos de intervención, se presentan en las figuras $5,6,7,8$ y 9 , respectivamente.

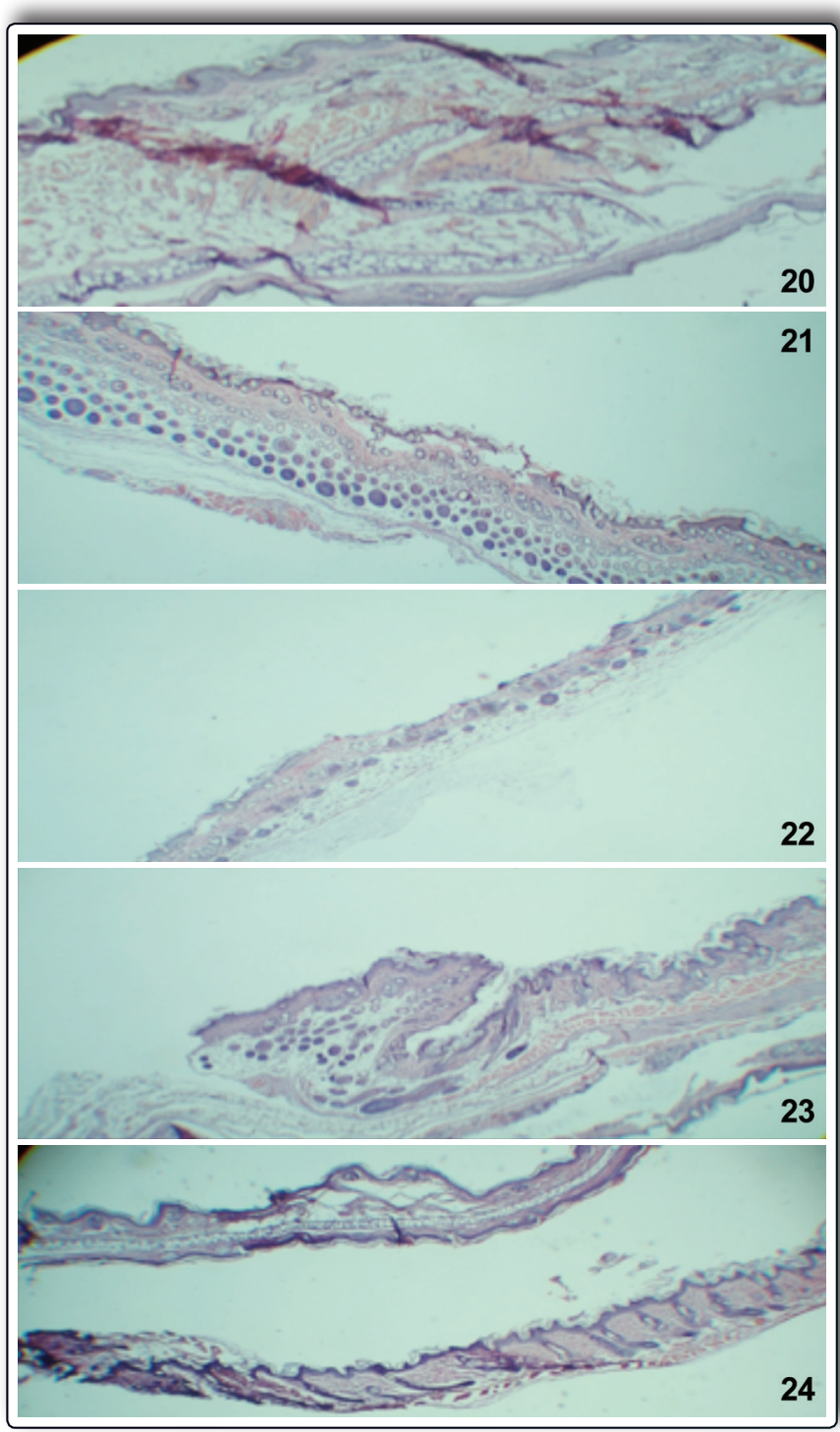

Figura 9. Cortes histológicos del grupo depilado, irradiado y tratado con pomada al $5 \%$ de extracto, H\&E, 100X. Capa córnea laminar fragmentada, epidermis delgada, presencia de tejido colágeno, microampollas en la dermis, moderada inflamación. 


\section{DISCUSIÓN}

Diversos estudios han demostrado que la piel sufre un proceso de envejecimiento debido a cambios cutáneos microscópicos y macroscópicos por la exposiciónal sol. Entre las causas de fotoenvejecimiento está la radiación ultravioleta (UVB) presente en la luz solar, la cual aumenta con el deterioro de la capa de ozono.

El fenómeno del fotoenvejecimiento se ha estudiado a través de modelos biológicos, in vivo e in vitro, con la aplicación de radiación ultravioleta evidenciando destrucción y/o desorganización de diferentes elementos constitutivos de la piel. Por ello es necesario conocer la acción tópica de productos naturales que inhiban o contrarresten estas alteraciones ${ }^{\left({ }^{8}\right)}$.

La luz solar modifica el contenido y la morfología de la matriz extracelular, que en su gran mayoría es sintetizada por los fibroblastos ${ }^{(9)}$, por lo tanto son productores de las fibras colágenas y elásticas que se encuentran alteradas en los animales irradiados ${ }^{(10)}$. La acantosis y la hiperqueratosis, entre otros factores, impiden el paso del agua transepidérmica. El déficit de agua va dando a la piel una apariencia seca, arrugada y escamosa ${ }^{(11)}$.

Estudios realizados sobre extractos de algas marinas con actividad antioxidante y reorganizadora de la fibra colágena, concluyeron que presentaban actividad antifotoenvejecimiento y propusieron el mejor de ellos para su uso en la preparación de cremas útiles contra las arrugas de la piel ${ }^{(4)}$. En este sentido, se ha evaluado el efecto de diversos compuestos, muchos de origen marino, pues la protección de estos organismos a la luz UV incluye sustancias que absorben estas radiaciones ${ }^{(12)}$. Un estudio realizado en cinco clases de macroalgas reportaron valores de IC50 desde 0,261 a $1,110 \mathrm{mg} / \mathrm{mL}$ frente al estándar BHT, referente sintético que mostró un $\mathrm{IC}_{50}$ de $\mathrm{o}, 011 \mathrm{mg} / \mathrm{mL}$, cuando fueron enfrentados a DPPH ${ }^{(13)}$. Estos resultados muestran que el estándar tiene una capacidad antioxidante de 24 a 100 veces mayor que las muestras de macroalgas, sin embargo aún se les considera como potenciales fuentes de antioxidantes.

El ensayo in vitro de la actividad antioxidante del extracto hidroalcohólico de las tres diferentes partes de esta alga mostró que existen entre ellas diferencias en la capacidad antioxidante frente al radical libre ABTS. El menor valor de $\mathrm{IC}_{50}(173,22 \mathrm{mg} / \mathrm{mL})$, obtenido en el extracto de fronda, expresa una mayor capacidad antioxidante total frente al valor de $\mathrm{IC}_{5} \mathrm{O}$ de $3,23 \mathrm{mg} /$ mL del Trólox, sin embargo no puede descartarse su actividad antioxidante porque se trata de un extracto que puede contener una serie de metabolitos cuyas actividades pueden añadirse $o$ inhibirse.

El ensayo CDP dio resultados a partir de la concentración $0,8 \mathrm{mg} / \mathrm{mL}$ en el extracto de fronda, el cuál mostró el menor $\mathrm{IC}_{50}$ en el ensayo con el radical catiónico ABTS. Las concentraciones menores fueron muy débiles -aun cuando el porcentaje de descomposición es un valor bajo- comparadas con el ácido ascórbico, quien sí es capaz de reducir a esta especie reactiva del oxígeno.

Al parecer la actividad antioxidante se da a través de la descomposición del peróxido de hidrógeno. Entonces el extracto hidroalcohólico puede ser considerado como un potencial antioxidante, útil en procedimientos que conduzcan a la separación e identificación de metabolitos capaces de atrapar radicales libres.

\section{CONCLUSIÓN}

El extracto hidroalcohólico del alga parda Macrocystis integrifolia Bory, vehiculizado en una forma dermocosmética, tiene efecto antioxidante in vitro y antifotoenvejecimiento in vivo.

\section{REFERENCIAS BIBLIOGRÁFICAS}

1. Graham MH, Vásquez JA, Buschman AH. Global ecology of the giant kelp Macrocystis: from ecotypes to ecosystems. Oceanografy and Marina Biology: An Anual Review 2007; 45: 39-88.

2. Benkeblia N. Free-Radical Scavenging capacity and antioxidant properties of some selected onions (Allium cepa L.) and garlic (Allium sativum L.) extracts. Brazilian Archives of Biology and Technology 2005; 48 (5): 735-9.

3. Chang HW, Jang KH, Lee D, et al. Monoglycerides from the brown alga Sargassum sagamianum: Isolation, synthesis, and biological activity. Bioorg Med Chem Lett. 2008; 18(12): 3589-92.

4. Concepción A, Fernández M, Fernández A, Mata A, Cruz T. Evaluación de extractos de algas marinas, con actividad antioxidante y reorganizadora de la fibra colágena. Rev Cubana Invest Biomed 2001; 20(1): 6-11.

5. Davis S, Lopjoch L, Kerr N, Fedesejirs R. Clothing as protection from ultraviolet radiation: which fabric is most effective?. Int J Dermatol 1997; 36 (5): 374-9.

6. Hazra B, Biswas S, Mandal N. Antioxidant and free radical scavenging activity of Spondias pinnata. BMC Complementary and Alternative Medicine 2008, 8: 63 BMC. [En línea]. Acceso 1o octubre 2013. Disponible en: http://www.biomedcentral.com/1472-6882/8/63. doi 10.1186/1472-6882-8-63.

7. Balasundram N, Ai TY, Sambanthamurthi R, Sundram K, Samman S. Antioxidant properties of palm fruit extracts, Asia Pac J Clin Nutr 2005; 14(4): 319-24. 
8. Gilchrest BA. A review of skin ageing and its medical therapy. Br J Dermatol 1966; 135(6): 867-75.

9. Bernstein EF, Uitto J. Effect of photodamage on dermal extracelular matrix. Clin Dermatol 1966; 14(2): 143-51.

10. Bernstein EF, Chen YQ, Kopp JB, Fisher L, Brown DB, Hahn PJ. Long-term sun exposure alters the collagen of the papillary dermis. Comparison of sunprotected and photoaged skin by northern analysis, immunohistochemical staining, and confocal laser scanning microscopy. J Am Acad Dermatol 1996; 34(2 Pt 1): 209-18.

11. Goldemberg RL. Functional aging. Drug and Cosmetic Industry 1995; 7: 68-71.

12. Dunlap WC. Chalker BE. Bandaranayake WH. Won J. Nature's sunscreen from the Great Barrier Reef, Australia. Int J Cosmet Sci 1998; 20(1): 41-51.
13. Echavarría B, Franco A, Martínez A. Evaluación de la actividad antioxidante y determinación del contenido de compuestos fenólicos en extractos de macroalgas del Caribe Colombiano. Vitae 2009; 16(1): 126-31. [En línea]. Acceso 12 setiembre 2013. Disponible en: http:// www.scielo.org.co/scielo.php?script=sci_arttext\&pid =So121-40042009000100015)

Manuscrito recibido el: 18/o9/14

Aceptado para su publicación el: 09/10/14

\section{Correspondencia:}

Nombre: Américo Jorge Castro Luna

Dirección: Jr. Puno 1002, Lima 1 - Perú E-mail: caslasha3@hotmail.com 